\title{
Research on the innovation of coordinated development of tourism and agriculture in Liaoning Province based on low carbon economy
}

\author{
Zhao Aihua ${ }^{1, *}$ \\ ${ }^{1}$ Eastern Liaoning University, Dandong, Liaoning Province, China
}

\begin{abstract}
In the era when countries all over the world advocate low carbon economy, the coordinated development of tourism and agriculture has become an inevitable trend. At present, Liaoning rural tourism has a great potential for development, the demand continues to grow, the market prospects are very broad. However, the integration degree of tourism and agriculture is still low, the product homogenization is serious, the infrastructure is backward, the service level is low. Taking Liaoning province as the research object, in a low carbon economy under the new situation, with the theory of grey correlation model, build a model of correlation between tourism and agriculture each factor interaction and coupling model, from two dimensions of time and space to study correlation between the two industries, as well as the coupling coordination degree distribution, put forward under the condition of low carbon economy the coordinated development strategy.
\end{abstract}

\section{Introduction}

Low carbon economy advocates the concept of green development. Under the guidance of the concept of sustainable development, the integration of tourism and agriculture can achieve a win-win situation of "rapid economic and social development" and "effective protection of ecological environment", which is the inevitable trend of social development. Liaoning is rich in tourism resources, and its tourism industry has a good development trend. At the same time, the agricultural and rural development of Liaoning has shown new vitality due to its obvious location advantage, and its comprehensive strength has been greatly enhanced. The research on the industrial integration of tourism and agriculture and the combination of the primary and tertiary industries can generate a new industry and economic growth point and promote the better development of Liaoning's industries. In this paper, the coupling coordination degree and grey correlation degree were used to establish a correlation model. Based on the data of tourism and agricultural development in Liaoning from 2010 to 2019,19 representative evaluation indicators were selected to conduct a quantitative analysis on the factors affecting the integrated development of tourism and agriculture in Liaoning. The entropy method was used to measure the weight of each index, and the coupling degree and coupling coordination degree of the integration of tourism and agriculture in Liaoning Province were measured by the coupling function and coupling coordination function. The results show that the coupling degree of the integrated development of tourism and agriculture in
Liaoning is 0.508 and 0.729 , which belongs to the good coordination level, which indicates that the interaction between the coupling of tourism and agriculture in Liaoning is great, and the coupling development space of the two industries is very large. The grey correlation model is used to carry out sequence matrix for 19 evaluation indexes of tourism and agriculture in Liaoning Province, and the data are dimensionless processed by range standardization method. According to the calculation of correlation degree formula, the per capita disposable income of rural residents has the strongest influence on the development of tourism, which indicates that the development of tourism depends on the effectiveness of farmers' income. Through the analysis of modeling data, it can be seen that the coordinated development of tourism and agriculture in Liaoning can greatly promote the integration and innovation development between industries, and bring sufficient impetus to the future economic development of Liaoning.

\section{Development status of tourism and agriculture development in Liaoning Province}

\subsection{Development status of tourism industry in Liaoning Province}

Liaoning is China's important heavy industry base, education province, tourism resources province. Liaoning has rich ethnic customs, numerous cultural

Z Zhao Aihua: aihua8663@sina.com 
relics and historic sites, and profound history and culture, abundant tourism resources and special multi-culture provide strong support for the development of Liaoning's tourism industry. Liaoning is located in the central region of Northeast Asia with obvious regional advantages, after the reform and opening up, tourism has developed rapidly and achieved remarkable results. As a traditional old industrial base, under the guidance of structural optimization development strategy, the tertiary industry in Liaoning has maintained a good development momentum. According to the Liaoning Provincial Bureau of 《 Statistical Communique of Liaoning Province on National Economic and Social Development in 2019》, in 2019, the added value of the tertiary industry in Liaoning was 1.3200 .4 billion yuan, up 5.6\%. Among them, the province received 64.1697 million domestic and foreign tourists, an increase of $13.6 \%$ over the previous year. The total tourism revenue reached 622.28 billion yuan, an increase of $15.9 \%$ over the previous year.

\subsection{Development status of agricultural industry in Liaoning Province}

Liaoning, as the old industrial base in northeast China, presents new vitality in agriculture and rural development with its superior location advantage and natural conditions. The total land area of Liaoning province is 148,600 square kilometers, and the cultivated land area is 41,600 square kilometers, accounting for $28.1 \%$ of the total land area. The sown area of grain crops in Liaoning province in 2019 was 3,488.7 thousand hectares, an increase of 4.7 thousand hectares over the previous year. The total grain output for the whole year was 24.300 million tons, 2.376 million tons more than that of the previous year, an increase of $10.8 \%$ and a record high. The added value of the province's primary industry reached 217.78 billion yuan, up $3.5 \%$. The percapita disposable income of permanent rural residents was 16,108 yuan, up $9.9 \%$. By the end of 2019, Liaoning had a permanent population of 43.517 million. Of these, 13.878 million, or $31.89 \%$, live in rural areas.

\section{Empirical analysis on the integration of Tourism and Agriculture in Liaoning Province}

More and more scholars take the integration of agriculture and tourism as the research object, and the research on the integration of agriculture and tourism was first carried out abroad. Lobo et al. (1999) took Santiago as the research area and studied the integrated development of agriculture and tourism, which is generally considered as the earliest study on the integration of agriculture and tourism ${ }^{[1]}$. Domestic scholars have also conducted research on both the fusion, through literature review, it can be seen that at present most of scholars focus on agriculture for the object to study the integration of both, mainly on tourism for development as well as the correlation of the fusion coordination degree of quantitative research is less, and the research from the perspective of industrial convergence of Liaoning tourism and the development of agriculture is still blank. For these reasons, this is also the significance of this study.

\subsection{The research methods}

Industrial convergence refers to the realization of technological convergence at the junction of industries due to technological progress and deregulation, which changes the original features of industrial products and the competitive and cooperative relationship between enterprises, thus leading to the blurring or even redrawing of the industry. Industrial coupling not only focuses on industrial integration, but also emphasizes that the integration at the intersection of industries and subsystems can maintain a close relationship and optimize the industrial structure between the parent and subsidiary systems. Industrial coupling has the same effect as industrial fusion. Industrial coupling can improve industrial efficiency, optimize industrial structure, promote independent innovation and promote industrial competitiveness. There is a coupling relation between tourism and agriculture. On the one hand, the development of agriculture lays a solid foundation for the development of tourism industry. On the other hand, the rapid development of tourism industry promotes the progress of agriculture. The dynamic interaction between the two can be studied by means of grey relational model and coupling theory.

\subsubsection{Coupling degree analysis}

Coupling refers to the phenomenon that two or more systems interact with each other in the process of movement or development, which is a dynamic relationship of mutual dependence, mutual coordination and mutual promotion under the benign interaction between each subsystem. Coupling degree is the degree of close relationship between the two, but also can be understood as the degree of interdependence.

\subsubsection{Grey relational analysis}

Grey correlation analysis method is a multifactor statistical analysis method, it is based on the factors of sample data described using grey correlation factors, on the strength of the relationship between size and sequence, if the two factors of sample data reflects the change of situation (direction, size and speed, etc.), then the correlation between them; on the contrary, the correlation degree is smaller.The advantage of this method lies in its clear thinking, which can greatly reduce the loss caused by information asymmetry, and has lower data requirements and less workload. Its main disadvantage is that it requires to determine the optimal value of each index, which is too subjective and difficult to determine the optimal value of some indexes. 


\subsection{Build the model}

Based on the previous research results and in line with the principle of data accuracy and inter-regional comparison, this paper measures the comprehensive development ability of the tourism industry from the two aspects of industrial performance and industrial factors at the tourism level. At the agricultural level, indicators are selected to evaluate the comprehensive development capacity of agriculture from four aspects, namely, agricultural input, agricultural output, agricultural economic structure and agricultural resource level. The data in this paper are from the Statistical Yearbook of Liaoning Province, China Tourism Statistical Yearbook and statistical bulletins of all regions of Liaoning Province from 2010 to 2019.

In this paper, according to the availability of tourism and agricultural data, the integration and coupling indexes of the two industrial systems are selected, as shown in Table 1.

Table 1: A research index system for integrated development of tourism and agriculture

\begin{tabular}{|c|c|c|}
\hline $\begin{array}{c}\text { Level1 } \\
\text { ndicators }\end{array}$ & $\begin{array}{l}\text { Level2 } \\
\text { indicators }\end{array}$ & Level 3 indicators \\
\hline \multirow{13}{*}{$\begin{array}{l}\text { The tourism } \\
\text { industry }\end{array}$} & \multirow{5}{*}{$\begin{array}{l}\text { Tourism } \\
\text { scale }\end{array}$} & $\begin{array}{l}\text { Number of domestic tourists } \\
\text { received }\left(X_{1}\right)\end{array}$ \\
\hline & & $\begin{array}{l}\text { Number of foreign tourists } \\
\text { received } \\
\left(\mathrm{X}_{2}\right)\end{array}$ \\
\hline & & $\begin{array}{l}\text { Number of hotels above star } \\
\text { level } \\
\left(\mathrm{X}_{3}\right)\end{array}$ \\
\hline & & $\begin{array}{l}\text { Number of national A-level } \\
\text { tourist attractions }\left(\mathrm{X}_{4}\right)\end{array}$ \\
\hline & & $\begin{array}{l}\text { Number of travel agencies } \\
\left(\mathrm{X}_{5}\right)\end{array}$ \\
\hline & \multirow{3}{*}{$\begin{array}{l}\text { Tourism } \\
\text { benefits } \\
\text { Tourism } \\
\text { development }\end{array}$} & $\begin{array}{l}\text { Domestic tourism revenue } \\
\left(\mathrm{X}_{6}\right)\end{array}$ \\
\hline & & $\begin{array}{l}\text { Foreign exchange income } \\
\text { from } \\
\text { international tourism }\left(\mathrm{X}_{7}\right)\end{array}$ \\
\hline & & $\begin{array}{l}\text { Added value of tertiary } \\
\text { industry }\left(X_{8}\right) \\
\text { Fixed assets investment in } \\
\text { tertiary industry }\left(X_{9}\right)\end{array}$ \\
\hline & \multirow{3}{*}{$\begin{array}{l}\text { Agricultural } \\
\text { scale }\end{array}$} & $\begin{array}{l}\text { Gross output value of } \\
\text { agriculture }\left(\mathrm{Y}_{1}\right) \\
\text { Total sown area of crops } \\
\left(\mathrm{Y}_{2}\right)\end{array}$ \\
\hline & & $\begin{array}{l}\text { Total power of agricultural } \\
\text { machinery }\left(\mathrm{Y}_{3}\right)\end{array}$ \\
\hline & & The rural population $\left(\mathrm{Y}_{4}\right)$ \\
\hline & \multirow[t]{2}{*}{$\begin{array}{l}\text { Agricultural } \\
\text { benefits }\end{array}$} & Total grain output (Y5) \\
\hline & & $\begin{array}{l}\text { Per capita disposable income } \\
\text { of rural } \\
\text { reside }\left(\mathrm{Y}_{6}\right)\end{array}$ \\
\hline
\end{tabular}

Agricultural

$\begin{array}{ll} & \text { industry }\left(\mathrm{Y}_{7}\right) \\ \text { Agricultural } & \text { Fixed assets investment in the } \\ \text { development } & \text { primary industry }\left(\mathrm{Y}_{8}\right) \\ & \text { Expenditure on rural water } \\ & \text { services } \\ & \left(\mathrm{Y}_{9}\right) \\ & \text { Per capita consumption } \\ & \text { expenditure of } \\ & \text { rural residents }\left(\mathrm{Y}_{10}\right)\end{array}$

\subsubsection{Coupling degree model analysis}

1) The measurement of industrial comprehensive index

(1)Data standardization processing

In the study, the influence of different units is first removed by dimensionless quantization, then coordinate translation is carried out, and a fixed value is added to avoid negative values, thus forming a new sequence of Numbers. The formula is as follows:

$$
x_{i j}^{\prime}=\frac{x_{i j}-\min _{i} x_{i j}}{\max _{i} x_{i j}-\min _{i} x_{i j}} \quad x_{i j}^{\prime} \in[0,1]
$$

(2)Entropy is a measure of the disorder degree of the system. If the information entropy of the index is smaller, the more information the index provides and the greater the role it plays in the comprehensive evaluation, the higher the weight should be. In this study, the entropy weight is defined as $w_{j}$

$$
w_{j}=\frac{1-e_{j}}{\sum_{j=1}^{n}\left(1-e_{j}\right)} \quad w_{j} \in[0,1], \quad \sum_{j=1}^{n} w_{j}=1
$$

(3) Two industry contribution degree calculation. The annual contribution of the cultural industry and tourism industry, namely the comprehensive development level, can be obtained by weighting the data obtained from the above formula. The higher the value, the better the development of the industry. Its formula is:

$$
G_{i}=\sum_{j=1}^{n} w_{j} x_{i j}^{\prime} \quad 0 \leq G_{i} \leq 1
$$

2) Measurement of coupling degree

The coupling degree of the two systems of cultural industry and tourism industry is expressed by $C$. In the calculation, the contribution degree of the two systems is set as $G_{i}^{1}, G_{i}^{2}$ respectively

$$
C_{i}=\frac{2 \sqrt{G_{i}^{1} G_{i}^{2}}}{G_{i}^{1}+G_{i}^{2}} \quad 0 \leq C_{i} \leq 1
$$


According to the calculated results, the coupling degree of the two systems can be classified as follows:

Table2: Classification table of coupling degree interval

\begin{tabular}{|c|c|}
\hline interval & The coupling \\
\hline 0 & There is no coupling \\
\hline $0<C<0.3$ & Low coupling \\
\hline $0.3 \leq C<0.7$ & Moderate coupling \\
\hline $0.7 \leq C \leq 1$ & Highly coupling \\
\hline
\end{tabular}

3 ) Measurement of coupling coordination degree

In this study, D was set as the degree of coupling coordination between the two systems, and its calculation formula was:

$$
D=\sqrt{C_{i} \times T_{i}}
$$

$$
T=\alpha G_{i}^{1}+\beta G_{i}^{2} \quad \alpha+\beta=1, \quad 0 \leq \alpha, \beta \leq 1 \quad T \in[0,1]
$$

Where $\mathrm{T}$ is the comprehensive harmonic index between tourism and agriculture. The coupling degree D of tourism and agriculture can be obtained from the coupling degree and the comprehensive harmonic index, which is between 0 and 1 and is divided into the following grades:

Table3: Standard for grading coupling coordination degree

\begin{tabular}{|l|l|l|l|}
\hline $\begin{array}{l}\text { Coupling } \\
\text { Degree of } \\
\text { the Two } \\
\text { Systems }\end{array}$ & $\begin{array}{l}\text { Coupled } \\
\text { coordination } \\
\text { state }\end{array}$ & $\begin{array}{l}\text { Coupling } \\
\text { Degree of } \\
\text { the Two } \\
\text { System s }\end{array}$ & $\begin{array}{l}\text { Coupled } \\
\text { coordination } \\
\text { state }\end{array}$ \\
\hline $0-0.09$ & $\begin{array}{l}\text { Extreme } \\
\text { imbalance }\end{array}$ & $0.50-0.59$ & $\begin{array}{l}\text { Barely } \\
\text { coordination }\end{array}$ \\
\hline $0.1-0.19$ & $\begin{array}{l}\text { A serious } \\
\text { imbalance } \\
\text { between }\end{array}$ & $0.60-0.69$ & $\begin{array}{l}\text { Primary } \\
\text { coordination }\end{array}$ \\
\hline $0.20-0.29$ & $\begin{array}{l}\text { Moderate } \\
\text { imbalance }\end{array}$ & $0.70-0.79$ & $\begin{array}{l}\text { Intermediate } \\
\text { coordination }\end{array}$ \\
\hline $0.30-0.39$ & Mild imbalance & $0.80-0.89$ & $\begin{array}{l}\text { Good } \\
\text { coordination }\end{array}$ \\
\hline $0.40-0.49$ & $\begin{array}{l}\text { On the verge of } \\
\text { imbalance }\end{array}$ & $0.90-1.00$ & $\begin{array}{l}\text { Quality } \\
\text { coordination }\end{array}$ \\
\hline
\end{tabular}

\subsubsection{Grey relational model analysis}

1) Set 10 sequences of comparison indicators to form the following matrix:

$$
\begin{gathered}
\left(X_{1}, X_{2} \cdots, X_{n}\right)=\left(\begin{array}{cccc}
x_{1}(1) & , x_{2}(1) & \cdots & , x_{n}(1) \\
x_{1}(2) & x_{2}(2) & \cdots & x_{n}(2) \\
\vdots & \vdots & \vdots & \vdots \\
x_{1}(\mathrm{~m}) & , x_{2}(\mathrm{~m}) & \cdots, & x_{n}(\mathrm{~m})
\end{array}\right) \\
X_{i}=\left(x_{i}(1), x_{i}(2) \cdots, x_{i}(m)\right)^{T}, i=1,2, \cdots, n
\end{gathered}
$$

among them $m$ Is the number of indicators.
Note: In the formula, $\mathrm{K}$ is the row index and $\mathrm{I}$ is the column index

2) Determine the reference indicator data series.Let the explanatory variable be Agricultural growth indicators, and the series be $\mathrm{Y}$ i $(\mathrm{K})(\mathrm{i}=1,2, \ldots, \mathrm{s} ; \mathrm{K}=$ $1,2, \ldots, \mathrm{n})$; explanatory variable $\mathrm{It}$ is an indicator of tourism development, and the series is $\mathrm{X} \mathrm{i}(\mathrm{K})(\mathrm{K}=$ $1,2, \ldots, \mathrm{n})$.

3 ) Dimensionless data processing, the index data sequence matrix after dimensionless is:

$$
\left(X_{0}^{\prime}, X_{1}^{\prime}, X_{2}^{\prime} \cdots, X_{n}^{\prime}\right)=\left(\begin{array}{ccccc}
x_{0}^{\prime}(1), & x_{1}^{\prime}(1) & x_{2}^{\prime}(1) & \cdots, & x_{n}^{\prime}(1) \\
x_{0}^{\prime}(2), & x_{1}^{\prime}(2), & x_{2}^{\prime}(2) & \cdots, & x_{n}^{\prime}(2) \\
\vdots & \vdots & \vdots & \vdots & \vdots \\
x_{0}^{\prime}(\mathrm{m}), & x_{1}^{\prime}(\mathrm{m}), & x_{2}^{\prime}(\mathrm{m}) & \cdots, & x_{n}^{\prime}(\mathrm{m})
\end{array}\right)
$$

4 ) Calculate the absolute difference between the index element (comparison sequence) of the evaluated object and the corresponding element of the reference sequence.

$$
\begin{gathered}
\left|x_{0}^{\prime}(k)-x_{i}^{\prime}(k)\right| \quad i=1,2, \cdots, n, \quad k=1,2, \cdots, m \\
\text { b) } \min _{i=1}^{n} \min _{k=1}^{m}\left|x_{0}^{\prime}(k)-x_{i}^{\prime}(k)\right|, \\
\max _{i=1}^{n} \max _{k=1}^{m}\left|x_{0}^{\prime}(k)-x_{i}^{\prime}(k)\right|
\end{gathered}
$$

5) Calculate the correlation coefficient:

$$
\begin{gathered}
\gamma\left(x_{0}^{\prime}(k), x_{i}^{\prime}(k)\right)=\frac{\min _{i=1}^{n} \min _{k=1}^{m}\left|x_{0}^{\prime}(k)-x_{i}^{\prime}(k)\right|+\rho \max _{i=1}^{n} \max _{k=1}^{m}\left|x_{0}^{\prime}(k)-x_{i}^{\prime}(k)\right|}{\left|x_{0}^{\prime}(k)-x_{i}^{\prime}(k)\right|+\rho \max _{i=1}^{n} \max _{k=1}^{m}\left|x_{0}^{\prime}(k)-x_{i}^{\prime}(k)\right|} \\
i=1,2, \cdots, n, \quad k=1,2, \cdots, m
\end{gathered}
$$

among them $\rho$ Is the resolution factor, $0<\rho<1$.

If $\rho$ The smaller the difference between the correlation coefficients, the stronger the discrimination

ability. $\rho$ Take 0.5 .

6 ) According to the correlation degree between tourism and agriculture in Liaoning province, the correlation degree was ranked from large to small, and the analysis results were obtained.

$$
\gamma\left(X_{0}^{\prime}, X_{i}^{\prime}\right)=\frac{1}{m} \sum_{k=1}^{m} \gamma\left(x_{0}^{\prime}(k), x_{i}^{\prime}(k)\right) \quad i=1,2, \cdots, n
$$

Table4: Analysis of grey correlation between Tourism and agriculture in Liaoning Province

\begin{tabular}{|c|c|c|c|c|c|}
\hline & $\mathrm{X}_{1}$ & $\mathrm{X}_{2}$ & $\mathrm{X}_{3}$ & $\mathrm{X}_{4}$ & $\mathrm{X}_{5}$ \\
\hline $\mathrm{Y}_{1}$ & 0.8098 & 0.5240 & 0.6592 & 0.7851 & 0.8721 \\
\hline $\mathrm{Y}_{2}$ & 0.6249 & 0.5986 & 0.5699 & 0.7952 & 0.8354 \\
\hline $\mathrm{Y}_{3}$ & 0.6968 & 0.6685 & 0.5105 & 0.7404 & 0.7399 \\
\hline $\mathrm{Y}_{4}$ & 0.6749 & 0.6889 & 0.5651 & 0.7650 & 0.7747 \\
\hline $\mathrm{Y}_{5}$ & 0.7280 & 0.6330 & 0.6486 & 0.8397 & 0.8604 \\
\hline $\mathrm{Y}_{6}$ & 0.9054 & 0.5289 & 0.7771 & 0.8017 & 0.8197 \\
\hline $\mathrm{Y}_{7}$ & 0.6769 & 0.5429 & 0.5348 & 0.6812 & 0.7709 \\
\hline $\mathrm{Y}_{8}$ & 0.5105 & 0.6770 & 0.4678 & 0.5517 & 0.5569 \\
\hline $\mathrm{Y}_{9}$ & 0.7589 & 0.5031 & 0.6042 & 0.7186 & 0.8303 \\
\hline
\end{tabular}




\begin{tabular}{|c|l|l|c|c|c|}
\hline $\mathrm{Y}_{10}$ & 0.8173 & 0.5085 & 0.8240 & 0.7319 & 0.7372 \\
\hline $\begin{array}{c}\text { The } \\
\text { average }\end{array}$ & 0.7204 & 0.5873 & 0.6161 & 0.7411 & 0.7797 \\
\hline $\begin{array}{c}\text { The } \\
\text { sorting }\end{array}$ & 4 & 7 & 6 & 3 & 1 \\
\hline
\end{tabular}

Table5: Analysis of grey correlation between Tourism and agriculture in Liaoning Province

\begin{tabular}{|c|c|c|c|c|c|c|}
\hline & $X_{6}$ & $X_{7}$ & $X_{8}$ & $X_{9}$ & $\begin{array}{c}\text { The } \\
\text { average }\end{array}$ & $\begin{array}{c}\text { The } \\
\text { sorting }\end{array}$ \\
\hline$Y_{1}$ & 0.7991 & 0.5034 & 0.887 & 0.4706 & 0.7013 & 2 \\
\hline$Y_{2}$ & 0.6869 & 0.5728 & 0.7214 & 0.5022 & 0.6643 & 6 \\
\hline$Y_{3}$ & 0.6660 & 0.6345 & 0.7026 & 0.5705 & 0.6509 & 8 \\
\hline$Y_{4}$ & 0.6856 & 0.6441 & 0.6743 & 0.5213 & 0.6659 & 5 \\
\hline$Y_{5}$ & 0.7417 & 0.6063 & 0.7494 & 0.5007 & 0.70089 & 3 \\
\hline$Y_{6}$ & 0.8328 & 0.5114 & 0.8688 & 0.4539 & 0.7221 & 1 \\
\hline$Y_{7}$ & 0.6773 & 0.5129 & 0.734 & 0.4615 & 0.6214 & 9 \\
\hline$Y_{8}$ & 0.5283 & 0.6696 & 0.5395 & 0.8193 & 0.5912 & 10 \\
\hline$Y_{9}$ & 0.7596 & 0.4787 & 0.7906 & 0.4184 & 0.6514 & 7 \\
\hline$Y_{10}$ & 0.7556 & 0.4926 & 0.7742 & 0.4403 & 0.6757 & 4 \\
\hline $\begin{array}{c}\text { The } \\
\text { average }\end{array}$ & 0.7133 & 0.5627 & 0.7443 & 0.5159 & & \\
\hline $\begin{array}{c}\text { The } \\
\text { sorting }\end{array}$ & 5 & 8 & 2 & 9 & & \\
\hline
\end{tabular}

\section{CONCLUSIONS AND ECOMMENDATI ONS}

\subsection{Results and analysis}

\subsubsection{Analysis of grey correlation between Tourism and agriculture in Liaoning province}

Based on each formula, the grey correlation between each index of tourism and the overall agricultural index of Liaoning province in 2019 and the grey correlation between each index of tourism and the overall agricultural index of Liaoning Province in 2019 are obtained respectively, and they are sorted by size (see Table 5). By comparing the correlation degree of each index, we can identify the impact degree of each index on the two industries.

Table6 : Correlation degree of Tourism and agriculture in Liaoning Province in 2019

\begin{tabular}{|c|c|c|c|c|c|}
\hline $\begin{array}{c}\text { Order } \\
1\end{array}$ & indicators & $\begin{array}{c}\text { Grey relational } \\
\text { degree }\end{array}$ & $\begin{array}{c}\text { Order } \\
2\end{array}$ & indicators & $\begin{array}{c}\text { Grey relational } \\
\text { degree }\end{array}$ \\
\hline 1 & $\mathrm{X}_{5}$ & 0.779744534 & 1 & $\mathrm{Y}_{6}$ & 0.722173661 \\
\hline 2 & $\mathrm{X}_{8}$ & 0.744273672 & 2 & $\mathrm{Y}_{1}$ & 0.701272176 \\
\hline 3 & $\mathrm{X}_{4}$ & 0.741071 & 3 & $\mathrm{Y}^{5}$ & 0.700887574 \\
\hline 4 & $\mathrm{X}_{1}$ & 0.72036049 & 4 & $\mathrm{Y}_{10}$ & 0.675748306 \\
\hline 5 & $\mathrm{X}_{6}$ & 0.713304562 & 5 & $\mathrm{Y}_{4}$ & 0.66599883 \\
\hline 6 & $\mathrm{X}_{3}$ & 0.6161223 & 6 & $\mathrm{Y}_{2}$ & 0.664374839 \\
\hline 7 & $\mathrm{X}_{2}$ & 0.58734326 & 7 & $\mathrm{Y}_{9}$ & 0.651374285 \\
\hline
\end{tabular}

\begin{tabular}{|c|c|c|c|c|c|}
\hline 8 & $\mathrm{X}_{7}$ & 0.562696471 & 8 & $\mathrm{Y}_{3}$ & 0.650865917 \\
\hline 9 & $\mathrm{X}_{9}$ & 0.515880486 & 9 & $\mathrm{Y}_{7}$ & 0.621447613 \\
\hline & & & 10 & $\mathrm{Y}_{8}$ & 0.591186767 \\
\hline
\end{tabular}

According to the calculation results of Ranking 1, it can be seen that the correlation degree of the nine indicators of tourism is above 0.5 . It shows that these 9 indicators have great influence on the comprehensive development of agriculture, and they are all important factors influencing the development of rural tourism. Among them, travel agencies $\left(\mathrm{X}_{5}\right)$ have the strongest influence on agricultural development, with the grey correlation degree reaching 0.7797 , which indicates the effective degree of support from travel agencies for rural tourism development. he second, fourth and fifth indexes that affect agricultural development are the added value of the tertiary industry $\left(\mathrm{X}_{8}\right)$, star hotels $\left(\mathrm{X}_{4}\right)$ and domestic tourism income $\left(\mathrm{X}_{6}\right)$, which indicates that the development level of the tourism industry has a direct impact on the development level of rural tourism. The correlation between the number of inbound tourists $\left(\mathrm{X}_{2}\right)$ and foreign exchange income from international tourism $\left(\mathrm{X}_{7}\right)$ and agriculture is relatively low, which is a medium correlation, indicating that these two indicators have a relatively weak impact on agricultural development compared with other indicators, indicating that the number of inbound tourists does not contribute much to agricultural development.

Similarly, according to the calculation results of Ranking 2, it can be seen that the correlation degree of the 10 agricultural indicators is above 0.5 , indicating that these 10 indicators have a certain impact on the comprehensive development of tourism. Among them, the per capita disposable income of rural residents $\left(\mathrm{Y}_{6}\right)$ has the strongest impact on the development of tourism, with the grey correlation reaching 0.7222 , which indicates the effective degree of tourism development relying on farmers' income. The second, fourth and fifth indexes that affect the development of tourism are total agricultural output $\left(\mathrm{Y}_{1}\right)$, total grain output $\left(\mathrm{Y}_{5}\right)$ and per capita consumption expenditure of rural residents $\left(\mathrm{Y}_{10}\right)$, which indicates that the living standards of farmers directly affect the development of tourism. The correlation between the total power of agricultural machinery $\left(\mathrm{Y}_{3}\right)$, the added value of the primary industry $\left(\mathrm{Y}_{7}\right)$, and the investment in fixed assets of the primary industry $\left(\mathrm{Y}_{8}\right)$ and tourism is relatively low, belonging to a medium correlation, indicating that these three indicators have a relatively weak impact on the development of tourism compared with other indicators.

\subsubsection{Analysis of coupling degree between Tourism and agriculture in Liaoning Province}

Based on the original data of tourism and agriculture in Liaoning province from October 2001 to 2019, the calculation formula of coupling coordination degree was used to calculate the following results: 
Table7: Corresponding types of coupling degree and coupling coordination degree between tourism and agriculture in Liaoning Province

\begin{tabular}{|c|c|c|c|c|c|}
\hline time & $\begin{array}{l}\text { Contribution of Tourism } \\
\text { Industry }\end{array}$ & $\begin{array}{c}\text { Contribution of } \\
\text { Agriculture }\end{array}$ & $\begin{array}{c}\text { Coupling Degree of the } \\
\text { Two Systems }\end{array}$ & $\mathrm{T}=\alpha \mathrm{G} 1+\beta \mathrm{G} 2$ & $\begin{array}{l}\text { Coupling Degree of the Two } \\
\text { Systems }\end{array}$ \\
\hline 2010 & 0.230981844 & 0.303803968 & 0.990685398 & 0.260110694 & 0.507629655 \\
\hline 2011 & 0.381414833 & 0.437177567 & 0.997677117 & 0.403719927 & 0.63465119 \\
\hline 2012 & 0.514520234 & 0.542455892 & 0.999650672 & 0.525694497 & 0.724921276 \\
\hline 2013 & 0.660467736 & 0.596763762 & 0.998715448 & 0.634986147 & 0.796348212 \\
\hline 2014 & 0.351712366 & 0.570003375 & 0.971550823 & 0.43902877 & 0.653099351 \\
\hline 2015 & 0.293350928 & 0.613314967 & 0.93566036 & 0.421336543 & 0.627875706 \\
\hline 2016 & 0.247193808 & 0.40218095 & 0.971100403 & 0.309188665 & 0.547953681 \\
\hline 2017 & 0.421019877 & 0.420878172 & 0.999999986 & 0.420963195 & 0.648816761 \\
\hline 2018 & 0.466272146 & 0.436201584 & 0.99944473 & 0.454243921 & 0.673789057 \\
\hline 2019 & 0.523721684 & 0.543355459 & 0.999830713 & 0.531575194 & 0.729030319 \\
\hline
\end{tabular}

Note: 0.6 for and 0.4 for in $\mathrm{T}$

The results show that, first, from the perspective of time series evolution, the coupling coordination degree between tourism and agriculture in Liaoning province shows a gradual upward trend from 2010 to 2019, indicating that tourism and agriculture promote each other and the degree of industry correlation is increasing ${ }^{[2]}$. Second, from the perspective of coupling coordination level, 2016-2017 is the stage of barely coordinated development between tourism and agriculture in Liaoning Province, 2017-2018 is the stage of primary coordinated development, and 2018-2019 is the stage of intermediate coordinated development. Thirdly, from the perspective of development stage, the evaluation index of Agriculture in Liaoning province from 2010 to 2012 is slightly higher than that of tourism, and agriculture drives the development of tourism. In 2013, tourism was rated significantly higher than agriculture; From 2014 to 2016, the evaluation index of agriculture is higher than that of tourism, indicating that agricultural development drives tourism at this stage. In 2017-2018, the evaluation index of tourism is obviously higher than that of agriculture, which indicates that the development trend of tourism at this stage is good, which promotes the development of agriculture, and the coupling between tourism and agriculture is in the best coordination state.

\subsection{Strategies to improve the integrated development of Tourism and agriculture in Liaoning under the rural revitalization strategy}

In line with the idea of promoting the deep integration and coordinated development of tourism and agriculture, this paper proposes the following strategies:

\subsubsection{Plan according to local conditions}

On the whole, we should give full play to the leading advantages of the tourism industry, promote agriculture by traveling, accelerate agricultural modernization development through the intervention of tourism, change the backward status of agriculture, and realize the development of double chain between agriculture and tourism. One is introduced to promote tourism and policy of agricultural integration, in speeding up the transformation of agriculture, comprehensive on the basis of synchronous development, advance the design of tourism products, tourism advertising on mining, tourism resources, vigorously develop the tourism industry, construct the tourism brand system of regional ethnic and cultural features, to raise their awareness ${ }^{[3]}$. Second, we should fully recognize and give play to the unique role of tourism in stabilizing growth, promoting reform, restructuring and benefiting people's livelihood, accelerate the convergence of various industries and tourism, thus accelerating the formation of a regionally wide tourism system, and ultimately promote the integrated development of the two industries together with the comprehensive level of agriculture.

\subsubsection{Attach great importance to resource integration}

In the process of the integration of tourism and agriculture, we must attach great importance to the integration of resources. Guiding the development of rural tourism to scale, intensification and characteristic development in the form of industrial cluster can optimize the industrial spatial distribution. In the process of rural tourism development, attention should be paid to the inheritance and education of farming and folk culture, which can not only enhance the cultural connotation of agricultural tourism products, but also enable tourists to combine education with entertainment, enhance the understanding of local rural culture in the pleasure of experience, and realize the improvement of effective demand while developing in a differentiated way. In terms of rural tourism products, they can be combined with folk culture to increase the interest and uniqueness of related products and gradually form a brand to drive the increase of added value. In terms of tourism agricultural products, in addition to extending the industrial chain and increasing refined products, folk culture can be used to increase the added value of local 
tourism agricultural products through featured designs with regional customs, product publicity with health care functions, etc., such as featured handicrafts and rural specialties.

\subsubsection{Promote integrated development of agriculture through tourism}

From the trend of the integration development of tourism and agriculture in Liaoning province from 2010 to 2019 , the degree of integration of the two industries is constantly improving, but it is only at the preliminary and intermediate coordination stage. The main reason lies in the low level of comprehensive development of tourism and agriculture respectively, among which the lagging trend of agriculture is obvious. In order to better integrate the two industries in Liaoning province, the development of agriculture needs to keep pace with the development of tourism. Therefore, in the leading areas of tourism industry, should give full play to the leading advantages of tourism industry. First of all, it is necessary to strengthen the driving force of tourism for agriculture and increase the consumption of agricultural products by tourism. For example, the growth of tourism consumption indirectly drives the demand of catering sector for agricultural and sideline products. In addition, relevant departments of agriculture should cooperate directly with tourism departments to find a breakthrough point and increase the direct consumption of tourism on agriculture according to the tourism demand of the market. Second, improve the innovation ability, build a multi-level, diversified tourism products system, excavation of the existing tourism resources and cultural connotation, enlarging the science and technology, promote the diversification of tourism products, and promote the rapid development of tourism industry, and the comprehensive benefit of feedback in the construction of rural tourism, to promote the development of agriculture. Third, do a good job in tourism marketing $^{[4]}$. Cultivate Liaoning's unique rural tourism brand through traditional means such as TV, billboards and radio, or Internet social platforms such as WeChat public account and weibo, so as to improve the attractiveness of rural tourism.

\section{Conclusion}

Under the background of advocating low-carbon economy all over the world, this paper, from the perspective of industrial integration, studies the correlation degree and coupling coordination degree between tourism and agriculture in Liaoning Province, highlights the interactive relationship between tourism and agriculture, and puts forward specific measures for their integration. These research strategy will be rich theoretical research contents of tourism and agriculture integration, tourism and agriculture in Liaoning province for two industrial convergence development related decisions more scientific and reasonable basis, to establish the interaction between the overall advantages of sharing to promote industrial upgrading of the tourism industry and agriculture in Liaoning province transformation, the promotion of the competitiveness of the rural tourism industry.

\section{Acknowledgments}

This paper is one of the stage achievements of the scientific research project "Research on the Integrated Development of Tourism and Agriculture in Liaoning Province under the Rural Revitalization Strategy" funded by the Education Department of Liaoning Province. (LNSJYT202011)

\section{References}

1.M Tian,F Zhou. Study on Tourism Development and Economic Growth Based on Grey $\mathrm{R}$ elational Analysis: Take Shandong Province As an Example, Journal of Chongqing University of Technology Natural Science.2019(2):208-215.

2.G.P. Zhou, The Coupling Between ECO-Agriculture and ECO -Tourism in Jiangsu $\mathrm{R}$ ovince, Chinese Journal of Agricultural $\mathrm{R}$ esources and $\mathrm{R}$ egional Planning.2018(4):226-231.

3.H. Zhang, Q. Zheng, X. L. Li. Study on The Development Countermeasures for The Integration of Agriculture and Tourism in Anhui Province, Journal of Jiangxi Science Technology Normal University.2018(4)42-49.

4.J. Ping, Y.H.Meng. Study on the Differences Between Projection Image and Tourist Perception Image of Tourist Destination: Case of Shiniuzhai Scenic Spot, Journal of Central South University of Forestry and Technology.2018(6)61-66. 